\title{
Comparative genomics reveals distinct host-interacting traits of three major human-associated propionibacteria
}

Tim N Mak', Monika Schmid ${ }^{2}$, Elzbieta Brzuszkiewicz ${ }^{3}$, Guanghong Zeng ${ }^{4}$, Rikke Meyer ${ }^{4}$, Karen S Sfanos ${ }^{5}$, Volker Brinkmann ${ }^{6}$, Thomas F Meyer ${ }^{7}$ and Holger Brüggemann ${ }^{1^{*}}$

\begin{abstract}
Background: Propionibacteria are part of the human microbiota. Many studies have addressed the predominant colonizer of sebaceous follicles of the skin, Propionibacterium acnes, and investigated its association with the skin disorder acne vulgaris, and lately with prostate cancer. Much less is known about two other propionibacterial species frequently found on human tissue sites, Propionibacterium granulosum and Propionibacterium avidum. Here we analyzed two and three genomes of $P$. granulosum and $P$. avidum, respectively, and compared them to two genomes of $P$. acnes; we further highlight differences among the three cutaneous species with proteomic and microscopy approaches.

Results: Electron and atomic force microscopy revealed an exopolysaccharide (EPS)-like structure surrounding $P$. avidum cells, that is absent in P. acnes and P. granulosum. In contrast, $P$. granulosum possesses pili-like appendices, which was confirmed by surface proteome analysis. The corresponding genes were identified; they are clustered with genes encoding sortases. Both, P. granulosum and P. avidum lack surface or secreted proteins for predicted host-interacting factors of $P$. acnes, including several CAMP factors, sialidases, dermatan-sulphate adhesins, hyaluronidase and a SH3 domain-containing lipoprotein; accordingly, only P. acnes exhibits neuraminidase and hyaluronidase activities. These functions are encoded on previously unrecognized island-like regions in the genome of $P$. acnes.

Conclusions: Despite their omnipresence on human skin little is known about the role of cutaneous propionibacteria. All three species are associated with a variety of diseases, including postoperative and device-related abscesses and infections. We showed that the three organisms have evolved distinct features to interact with their human host. Whereas P. avidum and P. granulosum produce an EPS-like surface structure and pili-like appendices, respectively, $P$. acnes possesses a number of unique surface-exposed proteins with host-interacting properties. The different surface properties of the three cutaneous propionibacteria are likely to determine their colonizing ability and pathogenic potential on the skin and at non-skin sites.
\end{abstract}

Keywords: Cutaneous propionibacteria, Propionibacterium acnes, Propionibacterium granulosum, Propionibacterium avidum, Exopolysaccharide, Pilus/pili, Surfome

\section{Background}

The genus Propionibacterium belongs to the phylum Actinobacteria and contains classical (or dairy) and cutaneous species. Whereas classical species such as Propionibacterium freudenreichii are considered to have probiotic effects [1] and are rather well characterized due to their importance in the dairy industry, cutaneous species are less well understood. The three most important cutaneous species are P. acnes, $P$. avidum and $P$.

\footnotetext{
* Correspondence: brueggemann@microbiology.au.dk

'Department of Biomedicine, Aarhus University, Aarhus, Denmark

Full list of author information is available at the end of the article
}

granulosum; these species can be found on the skin of virtually every human being, and they are also found on other tissue sites, including the gastrointestinal tract, lungs, and the prostate [2-6]. As part of the skin microbiota, both $P$. acnes and P. granulosum are found in sebaceous-rich areas, but $P$. acnes predominates in areas such as scalp, forehead, ear, back, and alae nasi [2,7]. $P$. avidum prefers moist rather than oily areas; it is found mainly in the anterior nares, axilla, and rectum [7].

The role of human-associated bacterial species belonging to the genus Propionibacterium is largely unknown; these species are described as commensals, saprophytes,

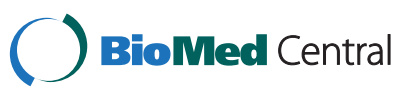


parasites or opportunistic pathogens. The pathogenic side of cutaneous propionibacteria, in particular P. acnes is slowly gaining attention. Apart from its possible role in acne vulgaris due to its immunostimulatory property, $P$. acnes has been associated with a number of other diseases $[8,9]$. Recently, P. acnes were found in diseased prostatic tissue $[5,6,10]$, and its contribution to prostate pathologies is currently under investigation. In our previous study, we isolated $P$. acnes, $P$. avidum and $P$. granulosum from radical prostatectomy specimens [10]. Little is known about the association of $P$. avidum and $P$. granulosum with human diseases. P. avidum has been found to cause abscess formation, in particular after surgical intervention; it has been described as the cause of abdominal wall and intra-peritoneal, perianal, psoas, splenic, and breast abscesses [11-13]. The disease association of P. granulosum is less clear, though it has been found in a few cases of endocarditis and endophthalmitis, and has been associated, like $P$. acnes, with sarcoidosis $[14,15]$.

It is not understood if all cutaneous propionibacteria have similar disease-causing potentials. The genome sequence of P. acnes and subsequent studies have highlighted hostinteracting factors such as CAMP factors, hemolysins, sialidases and dermatan-sulphate adhesins [16-20]. To date it is not clear if these factors are shared in all cutaneous propionibacteria. Here, we provide genomic insight into P. avidum and $P$. granulosum, and compare these genomes to $P$. acnes. We also performed electron microscopy and atomic force microscopy analysis on these species to further highlight differences among cutaneous propionibacteria. Together with proteomic data, our study highlights the individuality of each of the three human-associated propionibacterial species. In particular, the distinct surface structures suggest that each species interacts differently with the human host, which likely results in distinct pathogenic potentials.

\section{Results \\ Comparative genome analysis of cutaneous propionibacteria}

Seven genomes were analyzed and compared, two of each species, P. acnes (strains 266 and KPA) and P. granulosum (strains DSM20700 and TM11), and three genomes of $P$. avidum (44067, ATCC25577 and TM16). Four genomes were available from public databases (P. acnes KPA171202 (KPA) (GenBank: AE017283) [16], P. acnes 266 (GenBank: CP002409) [21], P. avidum 44067 (CP005287) [22] and P. avidum ATCC25577 (GenBank: NZ_AGBA00000000)) and we draft sequenced three additional ones (P. granulosum DSM20700 and TM11) and $P$. avidum TM16. P. granulosum TM11 and P. avidum TM16 were both isolated from radical prostatectomy specimens [10], and P. avidum 44067 was isolated from a human skin abscess [22]. P. avidum ATCC25577 and P. granulosum DSM20700 are both type strains.
First analysis revealed the much smaller genomes of the two $P$. granulosum strains, which is in average $400 \mathrm{~kb}$ smaller than $P$. acnes and $P$. avidum (Additional file 1). A bidirectional Blast revealed the core genome and species-specific genes of cutaneous propionibacteria (Figure 1; Additional file 2). 1380 proteins are common to all three species (Figure 1b). KEGG analysis showed that this core genome encodes main metabolic pathways, including the propionate formation pathway, the respiratory chain and the fatty acid metabolism (data not shown). $P$. acnes proteins encoded by the core genome show in average $89 \%$ and $73 \%$ identity to homologs of $P$. avidum and P. granulosum, respectively. This is in agreement with phylogenetic analyses based on 16S rRNA gene sequences, showing that $P$. acnes and $P$. avidum are closely related, whereas $P$. granulosum is more distant (data not shown).

Larger and smaller species-specific genomic islands were identified (Figure 1a; Additional files 2 and 3). Most of these are associated with a significant divergence from the main $\mathrm{G}+\mathrm{C}$ content, which could indicate horizontal gene transfer (HGT) events. For example, the two genomes of $P$. acnes contain larger regions $(>10 \mathrm{~kb})$ not present in $P$. avidum and $P$. granulosum; these encode among others non-ribosomal peptide synthetases (PPA1277-PPA1307), and harbor genes for nitrate reductase and anaerobic dimethyl sulfoxide reductase (PPA0497-PPA0520) (Additional file 2a). Other interesting results of comparative genome analyses are reported in the next sections.

\section{Absence of host-interacting, putative virulence factors in the genomes of $P$. avidum and $P$. granulosum}

Genome sequencing of $P$. acnes revealed the existence of five Christie-Atkins-Munch-Petersen (CAMP) factors $[16,17]$. At least three of these, CAMP factors 1, 2 and 4, are produced as either secreted or surface-exposed proteins $[17,23]$. It has been shown that at least CAMP factor 2 has properties of a co-hemolysin and exotoxin $[24,25]$. Genome analysis revealed now that the genes camp1, camp2 and camp4 are absent from the genomes of $P$. avidum and P. granulosum. The latter genome carries only one CAMP factor gene, designated here CAMP factor 6 (H640_02108 in strain TM11; H641_03053 in strain DSM20700), since it has no strong similarity to one of the five CAMP factors of $P$. acnes. $P$. avidum contains two CAMP factor genes with high similarities to CAMP factors 3 and 5, respectively (HMPREF9153_0708 and HMPREF9153_1759 in strain ATCC25577). Interestingly, when comparing the genomic regions containing the camp1, camp2 and camp4 genes in P. acnes with the genome of $P$. avidum, we noticed that the CAMP factor genes are encoded on genomic island-like regions (Figure 2). For example, the camp2 gene is inserted as part of a six-gene 


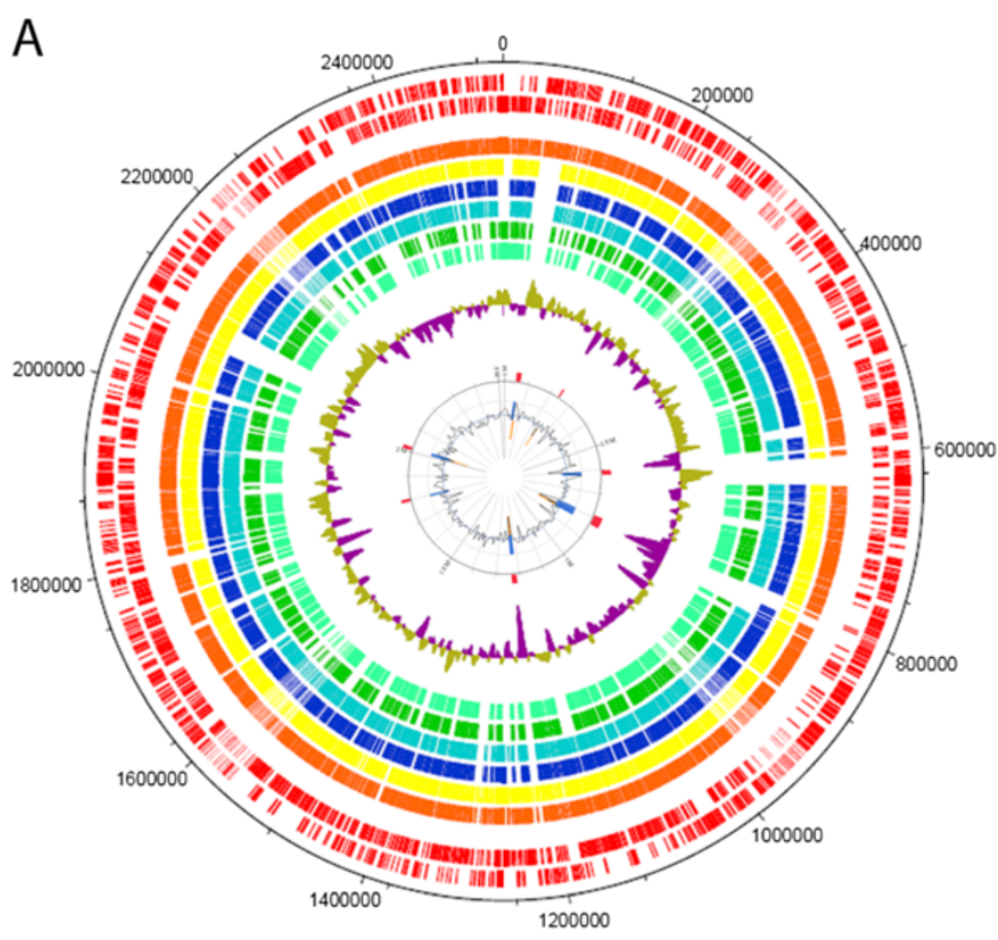

\section{B}

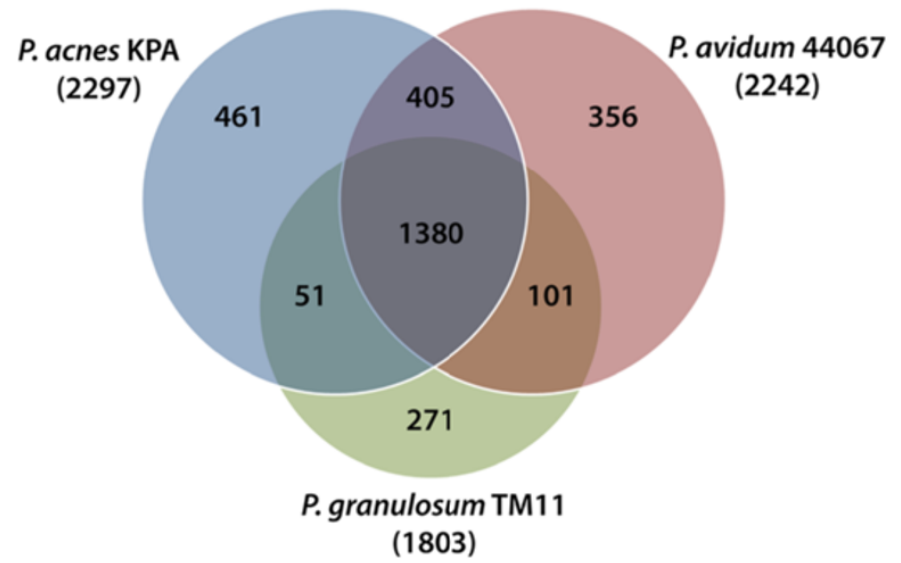

Figure 1 Genome comparison of three propionibacteria. A) All CDS of P. avidum 440677 (two red outer rings, representing CDS on plus and minus strand) were compared by bidirectional blast with all CDS of P. avidum ATCC25577 (orange) and P. avidum TM16 (yellow), P. acnes KPA (blue), P. acnes 266 (light blue), P. granulosum TM11 (green), and P. granulosum DSM20700 (marine). Gaps indicate the absence of CDS homologs of P. avidum 44067 in the respective genomes. The inner ring (in purple and olive) represents the $\mathrm{G}+\mathrm{C}$ content distribution of the $P$. avidum 44067 genome (window size $10000 \mathrm{bp}$, step size $200 \mathrm{bp}$ ). The most inner circle depicts predicted islands (in red) possibly acquired by horizontal gene transfer (predictions from IslandViewer; results from two different algorithms are shown: orange, Sigi-HMM; blue, IslandPath-DIMOB). P. avidum harbors 7 genomic regions that are predicted to be horizontally acquired. Please see also Additional file 3 for the genome comparisons of P. granulosum TM11 and P. acnes KPA. B) A VENN diagram depicts the number of species-specific CDS and those shared by all three propionibacteria. The three-way comparison is based on bidirectional blast results (Additional file 2). 1380 CDS have homologs in all three propionibacteria (>25\% amino acid identity), which represents 76\%, 61\% and 60\% of all CDS in P. granulosum TM11, P. avidum 44067 and P. acnes KPA, respectively.

cluster into the backbone genome. This cluster also contains two genes encoding sialidases (PPA0684, PPA0685) and a sialic acid transporter (PPA0686). The camp1 containing region is replaced in $P$. avidum with a region of eight genes encoding a putative arsenate reductase and transposases, underlining the mobile nature of this genomic region. The camp4 region is replaced in $P$. avidum with an island-like region of 13 genes, encoding among others a type I restriction-modification system.

Besides the camp genes also other predicted hostinteracting factor-encoding genes of $P$. acnes are absent from the genomes of $P$. avidum and $P$. granulosum, 
A

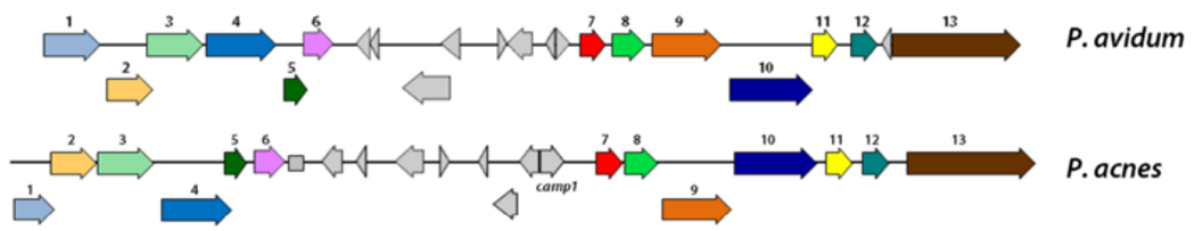

B

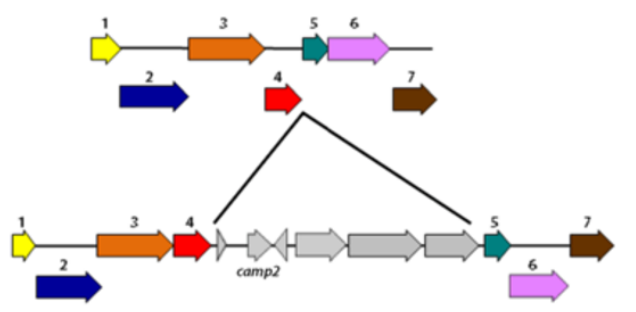

P. avidum

C

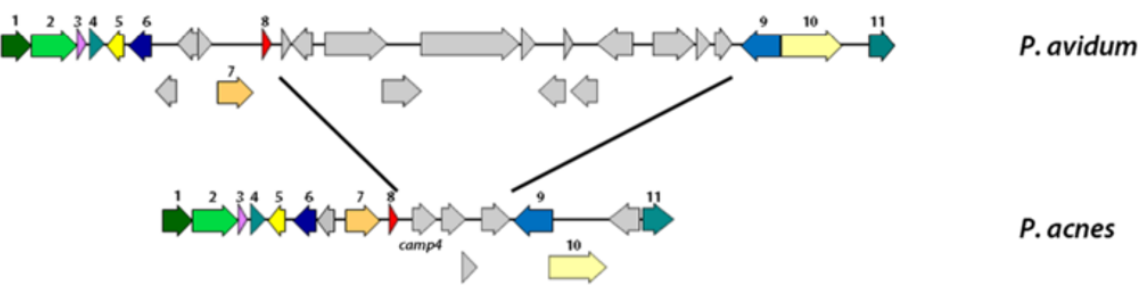

Figure 2 CAMP factor encoding loci of the $P$. acnes genome are absent from the $P$. avidum genome. A) CAMP factor 1 (PPA1340) in the $P$. acnes KPA genome is encoding within a gene cluster, that is replaced by a different cluster in $P$. avidum. Adjacent genes to this gene cluster are conserved in both genomes. Same color and number depicts homologs. B) CAMP factor 2 (PPA0687) of P. acnes is clustered with five other genes, encoding sialidases and a sialic acid transporter. This gene cluster is absent in the genome of $P$. avidum. C) CAMP factor 4 (PPA1231) and three adjacent genes of $P$. acnes KPA are replaced in the genome of $P$. avidum by a larger gene cluster. $P$. avidum ATCC25577 was used for this illustration; the genome of $P$. avidum TM16 is identical in the depicted genomic regions.

including a hyaluronate lyase (PPA0380), the two dermatan-sulphate adhesins DsA1 and DsA2 [18,19], and other proline-threonine repeat-motif proteins (PPA1880, PPA1715) (Additional file 4). Furthermore, the characterized sialidase (PPA1560) that has been shown to have a role in $P$. acnes adhesion and cytotoxicity [20], is truncated in P. avidum ATCC25577 and absent from $P$. avidum 44067 and $P$. granulosum DSM20700 and TM11. We tested the sequenced strains for hyaluronidase and neuraminidase activities: only the $P$. acnes strains were positive (data not shown), thus confirming findings from genome analyses.

\section{$P$. avidum produces an exopolysaccharide-like structure}

The search for species-specific genomic regions identified a large genomic island, present in all $P$. avidum genomes (HMPREF9153_1223 to HMPREF9153_1257 in strain ATCC25577; PALO_09550 to PALO_09690 in strain 44067), that is absent from $P$. acnes and $P$. granulosum (Additional file 2b). This region harbors 35 genes (in strain ATCC25577), 19 of them encode glycosyl transferases and enzymes involved in mono- or polysaccharide modification. We noticed a similarity of this cluster to a 20-gene cluster found in the genome of Rothia mucilaginosa, a Gram-positive, coagulasenegative coccus that is part of the commensal flora of the oral cavity and the upper respiratory tract in humans (Additional file 5a). R. mucilaginosa produces a thick exopolysaccharide (EPS)-like structure [26]; thus, we applied electron microscopy to examine the cell morphology of $P$. avidum. We observed a meshwork structure surrounding cells of $P$. avidum that was absent from $P$. acnes and P. granulosum (Figure 3 ), and that is very similar to the meshwork structures surrounding $R$. mucilaginosa. Atomic force microscopy further confirmed the presence of an extracellular structure of $P$. avidum extending several $\mu \mathrm{m}$ from the cell surface (Figure 4). The AFM imaging excludes the possibility of artifacts caused by the vacuum environment of the electron microscope, but the structure did collapse on to the cell surface and underlying glass substrate upon gentle air drying of the sample. It is probably a highly hydrated and amorphous material when in aqueous solution, as it appears more amorphous rather than filamentous in structure at the cell surface where 

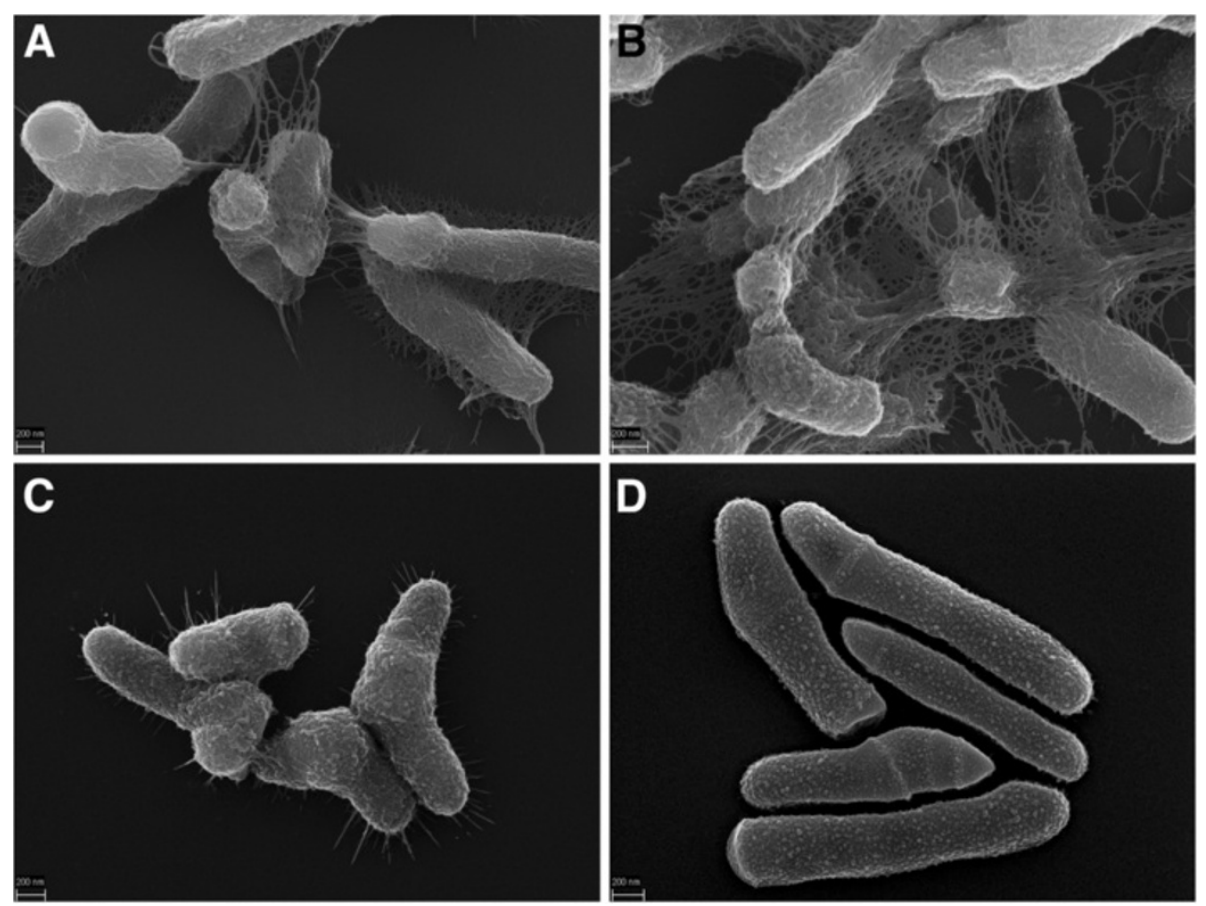

Figure 3 Electron microscopic images of three propionibacteria. Shown are representative images of A) P. avidum ATCC25577; B) P. avidum TM16; C) P. granulosum DSM20700, and D) P. acnes KPA. P. avidum cells are surrounded by a meshwork structure. P. granulosum cells have appendices similar to fimbriae or pili.

some level of hydration remains. To investigate the composition of this structure, we used specific fluorescent stains for DNA and for carbohydrates (Additional file 5b), which revealed that the structure is made of polysaccharides containing $\beta-1,4$ or $\beta-1,3$ bonds.

\section{P. granulosum possesses pili-like appendices}

Electron microscopy further revealed pili- or fimbriaelike appendices on the cell surface of $P$. granulosum (Figure 3C). Such structures were not detected on the surface of $P$. acnes and $P$. avidum. Pili or fimbriae are found in several Gram-positive bacteria, including some species of the related genus Corynebacterium [27]. In Corynebacterium sp. pilin subunits are encoded in several gene clusters that also contain genes for pilinspecific sortases. In a search for such gene clusters in the genome of P. granulosum we found two gene clusters that encode multiple sortases (designated SrtA-D; H641_03530, H641_03545, H641_05823, H641_05838 in strain DSM20700) and homologs of several pilin subunits of Corynebacterium sp., namely the major pilin $\mathrm{SpaD}$ and minor pillins $\mathrm{SpaB}, \mathrm{SpaC}, \mathrm{SpaF}$ and SpaI (Figure 5). These two clusters are absent from the genomes of $P$. acnes and $P$. avidum. The Spa-like proteins possess a typical LPXTG sorting motif for anchoring at the $\mathrm{C}$-terminus, and a $\mathrm{N}$-terminal signal peptide. In order to investigate which proteins are involved in pilus formation in $P$. granulosum we identified surfaceattached proteins via a surfome approach (see below). Two pilin subunits were identified in strain DSM20700, namely homologs of SpaD (H641_05818) and SpaB (H641_03535) that are $33 \%$ and $35 \%$ identity to SpaD and $\mathrm{SpaB}$ of Corynebacterium ulcerans and Corynebacterium resistens, respectively (Table 1 ). The SpaD homolog could represent the major subunit of the pilus, and the SpaB homolog could be a minor pilin, in analogy to the SpaD-type pilus of Corynebacterium diphtheria [27].

\section{Secreted and surface-associated proteins of $P$. avidum, $P$. granulosum and $P$. acnes}

We determined main secreted and surface-attached proteins of the three cutaneous propionibacteria, since such proteins could mediate the contact with human tissue sites, and could reveal host-interacting strategies. For determining secreted proteins, we collected culture supernatants, precipitated the secreted proteins and identified prominent bands on a 1D-SDS-PAGE gel by mass spectrometry (Additional file 6). For P. avidum ATCC25577 the main secreted protein, under the applied growth conditions, is a triacylglycerol lipase that is $48 \%$ similar to GehA (PPA2105), a characterized lipase of P. acnes. Furthermore, a homolog of CAMP factor 3 and several proteins of unknown function could be detected in the supernatant of $P$. avidum ATCC25577 (Additional file 7). 

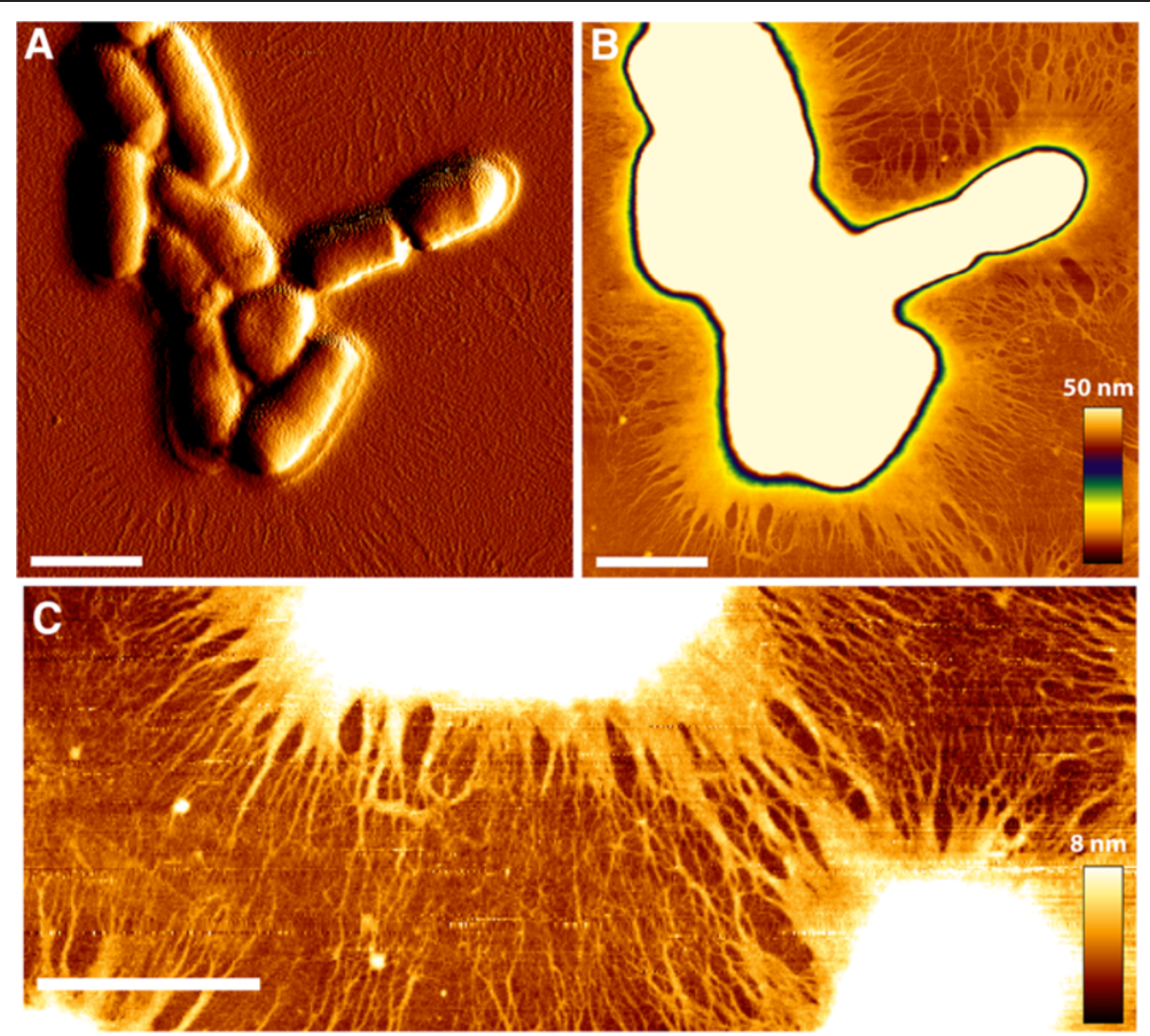

Figure 4 Atomic force microscopy of $P$. avidum ATCC25577. A) Amplitude image of the overall morphology of the cells. Extracellular structures are clearly visible, extending out from the cell surface. B) and C) Height images showing extracellular structures collapsed onto the glass coverslip. The fiber-like structures measure $1-3 \mathrm{~nm}$ in diameter. $X-Y$ scalebar $=1 \mu \mathrm{m}, \mathrm{z}$ scale is indicated by color.

All identified eight secreted proteins of $P$. avidum have a homolog in P. acnes; five of eight homologs have also been detected in $P$. acnes supernatants [23]. $P$. granulosum DSM20700 abundantly secretes two proteins, with peaks in the beginning of the stationary phase: two predicted lysophospholipases that are 53\% and $56 \%$ similar to a putative lysophospholipase (PPA2142) of P. acnes (Additional files 6 and 7). Homologs of all secreted proteins in $P$. granulosum have been detected in culture supernatants of $P$. acnes [23]. Homologs of one protein (PPA0532) are secreted by all cutaneous propionibacteria; the function of PPA0532 is unknown. Our previous study has shown that $P$. acnes, regardless of the specific subtype, abundantly secretes CAMP factor 2, a putative lysozyme (PPA1662), an endoglycoceramindase (PPA0644), and a protein of unknown function (PPA1939) [23]. Homologs of none of these proteins were detected in culture supernatants of P. avidum ATCC25577 or P. granulosum DSM20700; the corresponding genes are absent from their genomes (Figure 2; Additional file 2a). This indicates that $P$. acnes secretes a unique set of factors.
The surface-exposed proteins were determined by a surfome-approach that is based on trypsin cleavage of surface-exposed protein moieties [28]. In all three Propionibacterium species the most abundantly detected surface-attached proteins were RlpA-domain containing lipoproteins (Table 1; Additional file 7). Two such proteins (PPA2175 and PPA2271) were detected on the surface of $P$. acnes. PPA2175 is exclusively produced by $P$. acnes; it contains a bacterial $\mathrm{SH} 3$ and a peptidoglycanbinding domain (Figure 6). The corresponding gene is absent from the genomes of $P$. avidum and $P$. granulosum. Homologs of the other lipoprotein, PPA2271, were also abundantly detected on $P$. granulosum DSM20700 (H641_02938) and P. avidum ATCC25577 (HMPREF9153_0971). Additional speciesspecific surface-attached factors were identified, e.g. CAMP factor 6 of P. granulosum. In P. acnes, CAMP factors 1 and 2 were detected as well as two endoglycoceramidases and two GroEL chaperonins (Additional file 7). The duplication of surface-exposed factors points to some redundancy, and could indicate that the duplicated factors are of high importance for P. acnes. 


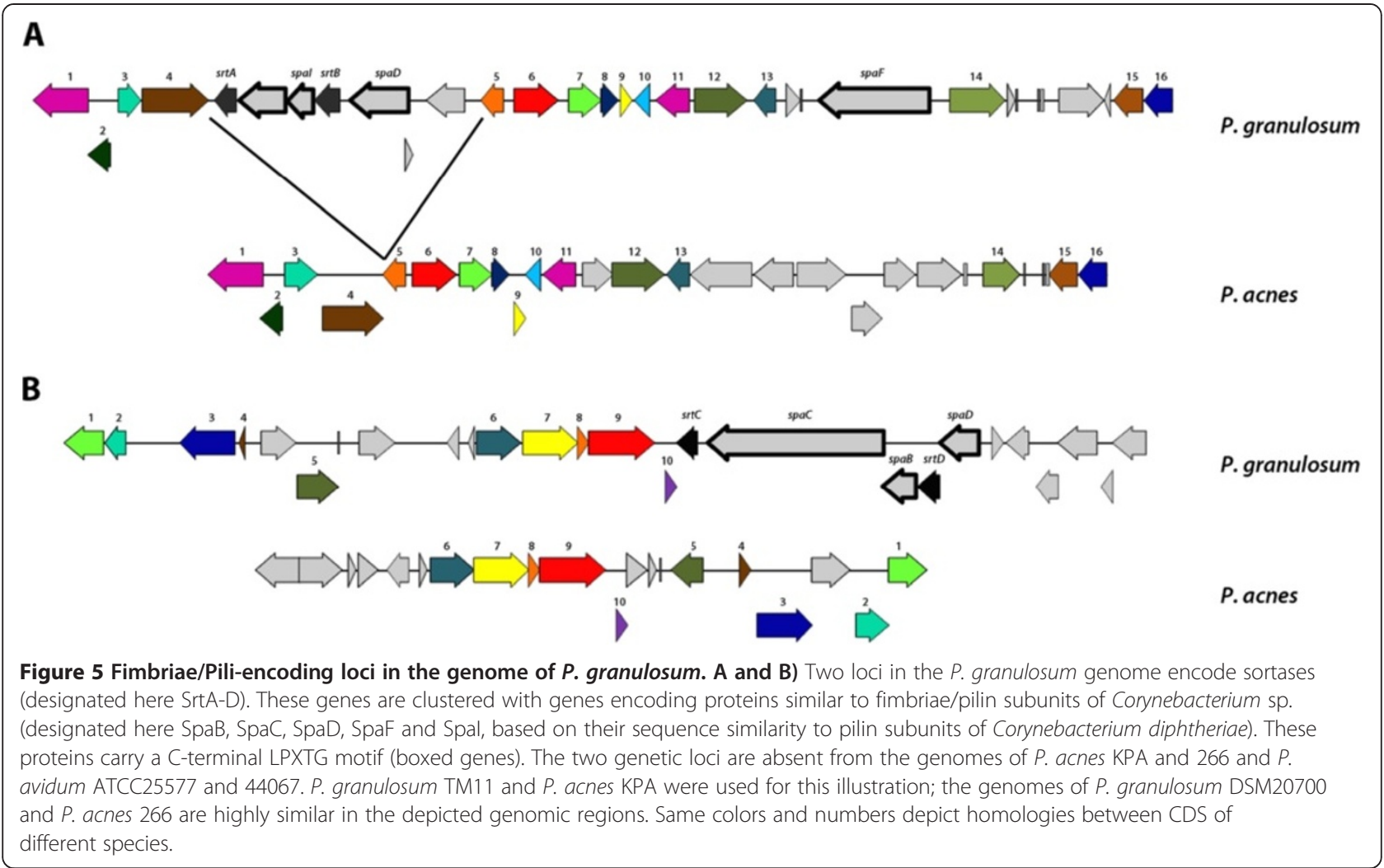

\section{Discussion}

Here, we analyzed and compared the genomes of the three propionibacterial species known to colonize the human skin. Species-specific gene clusters were identified in each genome that encode traits for colonization and host-interaction. Applying high-resolution microscopy and proteomic approaches we could verify the production of these surface-associated functions.

P. avidum was found to be surrounded by an EPS-like meshwork. A gene cluster that encodes proteins involved in the biosynthesis and modification of EPS was identified. The cluster encodes several homologs for enzymes involved in LPS and EPS biosynthesis (RfbA, RfbB, RfbD, RfaG, ExoU, NeuA, NeuB) as well as a number of glycosyl transferases with unknown specificities. RfbA, B, D are found in Lactococcus lactis, and required for dTDPrhamnose biosynthesis, which is an important precursor of rhamnose-containing exopolysaccharides [29]. The genes $n e u A$ and $n e u B$ are found in the LPS biosynthesis gene clusters of several Gram-negative species. NeuA and NeuB have been shown to be important in polysialic acid capsule biosynthesis [30]. The P. avidum EPS gene cluster lacks a gene for a flippase, indicating that the EPS structure is formed on the outside of the cell. Interestingly, the cluster also contains genes involved in trehalose biosynthesis (TreY-TreZ pathway). The disaccharide trehalose can protect cells from environmental stresses such as low water availability [31]. 20 of the 35 genes have a homolog in $R$. mucilaginosa that produces a mucilaginous capsular material [26]. Like P. avidum, R. muciloginosa is occasionally isolated from disease sites, thus regarded as an opportunistic pathogen, for instance involved in prosthetic device infections. Well-studied EPS in other bacteria, such as in Pseudomonas aeruginosa, have several roles in pathogenicity; EPS contributes to biofilm formation, adherence to surfaces and host cells, evasion of phagocytosis, and elicitation of immune response [32-34]. We hypothesize that the EPS structure of $P$. avidum could have a role in biofilm formation, and thereby contribute to its pathogenicity by leading to persistent infections that cannot be cleared by the immune system. This might explain why $P$. avidum is in particular recognized in abscess formation after surgical intervention [11-13,22]. It should be noted that several studies reported the presence of a cell wall-associated polysaccharide of $P$. acnes that can partially be extracted by phenol extraction [35-37]. Such a cell wall polysaccharide was further described as a lipidated macroamphiphile; this lipoglycan cell envelope component of $P$. acnes was found to have a lipid anchor and a polysaccharide moiety containing mannose, glucose and galactose, and probably diaminohexuronic acid [38]. We strongly suspect that the lipoglycan of $P$. acnes is distinct from the EPS of $P$. avidum. We tested different strains of $P$. acnes grown under different conditions and could not 
Table 1 Selected surface-associated factors of $P$. avidum, $P$. granulosum and $P$. acnes identified from surface proteome analysis

\begin{tabular}{|c|c|c|c|c|c|}
\hline Locus tag & Size (kDa) & Function & Score & Matches & P. acnes homolog \\
\hline \multicolumn{6}{|c|}{ P. avidum ATCC25577 } \\
\hline HMPREF9153_0971 & 53.0 & Rare lipoprotein A (RlpA family) & 747 & 18 & PPA2271 (76\%) \\
\hline HMPREF9153_0397 & 33.6 & Glutamine/glutamate ABC superfamily ATP binding cassette Transporter & 601 & 15 & no \\
\hline HMPREF9153_1303 & 60.9 & Peptidase (SlpE) & 349 & 10 & PPA0247 (78\%) \\
\hline HMPREF9153_0820 & 87.7 & Penicillin-binding protein PonA & 321 & 4 & PPA2149 (89\%) \\
\hline HMPREF9153_0967 & 26.2 & Hypothetical protein & 292 & 6 & no \\
\hline \multicolumn{6}{|c|}{ P. granulosum DSM20700 } \\
\hline H641_02938 & 63.1 & Rare lipoprotein A (RlpA family) & 1290 & 24 & PPA2271 (39\%) \\
\hline H641_04819 & 36.9 & Hypothetical protein & 1159 & 19 & no \\
\hline H641_08540 & 56.6 & Conserved hypothetical protein & 1077 & 13 & no \\
\hline H641_04393 & 61.1 & Hypothetical protein & 921 & 15 & PPA0444 (72\%) \\
\hline H641_03802 & 41.2 & Rare lipoprotein A (RlpA family) & 803 & 11 & PPA2239 (64\%) \\
\hline H641_06353 & 84.5 & Phosphoesterase & 540 & 9 & PPA1745 (66\%) \\
\hline H641_03053 & 29.4 & CAMP factor 6 & 533 & 8 & PPA0687 (41\%) \\
\hline H641_07095 & 41.2 & Putative lysophospholipase & 509 & 7 & PPA2142 (56\%) \\
\hline H641_05818 & 60.2 & SpaD homolog & 375 & 6 & no \\
\hline H641_03535 & 42.2 & SpaB homolog & 222 & 3 & no \\
\hline \multicolumn{6}{|c|}{ P. acnes KPA171202 } \\
\hline PPA2175 & 36.5 & Rare lipoprotein A (RIpA family) & 2923 & 47 & \\
\hline PPA2271 & 52.2 & Rare lipoprotein A (RlpA family) & 2666 & 42 & \\
\hline PPA0644 & 56.6 & Endoglycoceramidase & 1113 & 13 & \\
\hline PPA2106 & 54.0 & Endoglycoceramidase & 1019 & 16 & \\
\hline PPA0721 & 40.7 & NPL/P60 family secreted protein & 674 & 12 & \\
\hline PPA1939 & 16.8 & Hypothetical protein & 639 & 12 & \\
\hline PPA2097 & 73.4 & 5'-nucleotidase/2',3'-cyclic phosphodiesterase or related esterase & 547 & 7 & \\
\hline PPA0687 & 28.6 & CAMP factor 2 & 394 & 4 & \\
\hline PPA2105 & 35.9 & Triacylglycerol lipase precursor & 353 & 4 & \\
\hline PPA2239 & 41.0 & Lipoprotein A-like protein & 342 & 5 & \\
\hline PPA1340 & 30.3 & CAMP factor 1 & 230 & 3 & \\
\hline
\end{tabular}

Listed are all surface-exposed proteins that possess a typical N-terminal signal peptide. See Additional file 7 for a complete list.

detect any EPS-like structure by EM analyses (data not shown). To our knowledge no study so far could visualize an EPS-like meshwork on P. acnes cells. Moreover, the identified putative EPS biosynthesis genes of $P$. avidum are absent from the genomes of $P$. acnes (and P. granulosum).

We found that $P$. granulosum possesses pili/fimbriaelike appendices and pilin subunits were identified among cell surface-exposed proteins of P. granulosum. We determined two gene clusters encoding pilin subunits in direct vicinity to genes encoding sortases. Such clustering of genes for sortase and pilin subunits has been reported for a number of Gram-positive bacteria, including related actinobacteria such as Corynebacterium diphtheriae that produces three distinct pilus structures,
SpaA-, SpaD- and SpaH-type pili [27]. In corynebacteria pilins are covalently polymerized and the formed pilus is anchored to the bacterial cell wall; these steps are catalyzed by pilin-specific and housekeeping sortases, respectively. It has been shown that minor pilins (SpaB/ $\mathrm{SpaC}$ ) represent the major adhesins of corynebacteria $[27,39]$. Thus, we hypothesize that pili of $P$. granulosum could have a role in adhesion to human skin tissue and colonization. They might also have a role in forming a multispecies biofilm, since $P$. granulosum and $P$. acnes are often detected together within sebaceous follicles. The anchorage of the base of the pilus to the cell wall is usually mediated by a housekeeping sortase [27]. A likely candidate for this housekeeping sortase was identified among the surface-associated proteins: H641_09423 
PPA2175 (HMPREF9153_0861 (75\%))

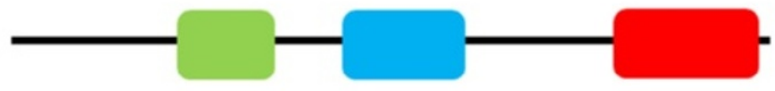

PPA2271 (HMPREF9153_0971 (76\%), H641_02938 (39\%))

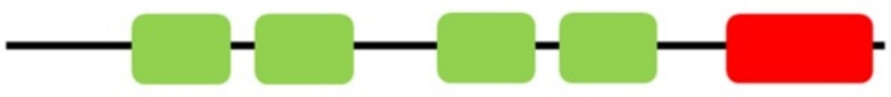

PPA2239 (HMPREF9153_0926 (92\%), H641_03802 (64\%))

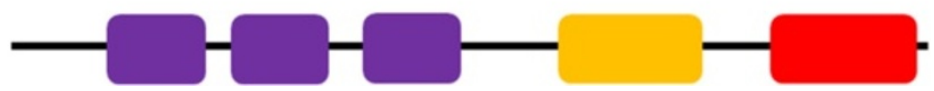

Figure 6 Domain architecture of surface-attached lipoproteins of propionibacteria. Propionibacteria produce lipoproteins with a RlpA domain that are attached to the cell surface. P. acnes KPA has three orthologs (PPA2172, PPA2271, PPA2239); these proteins are abundantly detected on the surface of $P$. acnes (PPA2175, PPA2271) or secreted (PPA2239). In brackets: orthologs in P. avidum ATCC25577 (HMPREF9153_X) and P. granulosum DSM20700 (H641_X). Legend: red, RlpA domain; green, SH3 domain; blue, peptidoglycan-binding domain; lila, DUF348 domain; orange, G5 domain.

(strain DSM20700), a protein with a sortase E domain. A homolog exists in P. acnes KPA (PPA0777) and in P. avidum ATCC25577 (HMPREF9153_2132). These sortases likely catalyze the anchoring of other LPXTGmotif proteins of the three propionibacterial species to their cell walls. A genome search revealed that P. avidum contains $12, P$. acnes 15 , and $P$. granulosum 18 proteins (including 7 putative pilin subunits) with a C-terminal LPXTG motif. Most of these LPXTG-motif proteins have no or little similarity to known proteins, exceptions are proteins with nucleotidase or phosphoesterase domains. Only few of these LPXTG-motif proteins have been identified in the surfome. That could either indicate that they were not or weakly expressed under the applied growth conditions (liquid culture, complex broth), or were not accessible for trypsin cleavage.

Analysis of the surfome data of P. granulosum further revealed the presence of several cytosolic proteins, including ribosomal proteins and those involved in core metabolic functions (methylmalonyl-CoA:pyruvate transcarboxylase $12 \mathrm{~S}$ subunit; two methylmalonyl-CoA mutases; fumarate hydratase class II; succinyl-CoA ligase). That indicates that $P$. granulosum seems to be more sensitive to trypsin treatment or lyse earlier than $P$. avidum and $P$. acnes.

$P$. acnes has, unlike $P$. granulosum and $P$. avidum, no obvious surface appendices. However, $P$. acnes is by far the most prevalent bacterium in sebaceous follicles of the face and back [2,7]. Thus, this species must have evolved a different strategy to adhere to and colonize human tissues. Surface proteins could act as powerful adhesins. Indeed, the dermatan-sulphate adhesins DsA1 and DsA2 have been identified and partially characterized in $P$. acnes $[18,19]$. These were not found in the surfome of the strain KPA, most likely because the respective genes are phase variable, but DsA1 and DsA2 are present on the surface of the type Ia strain 266 (data not shown). In addition, the surfome data revealed an abundance of lipoproteins with RlpA (rare lipoprotein A) domains on the surface of $P$. acnes. The bacterium specifically produces PPA2175 on the surface; it contains a SH3 and a peptidoglycan-binding domain (Figure 6). Bacterial lipoproteins have diverse functions; they play roles in a wide range of physiological processes. They can also function as ligands of the innate immunity host cell receptor Toll-like receptor 2 (TLR2), thus triggering an innate immune reaction [40]. It has been reported that TLR2 was sufficient for NF-kappaB activation in response to $P$. acnes and activation of TLR2 resulted in an inflammatory cytokine response, which is thought to be of crucial importance in acne vulgaris $[41,42]$. The TLR2 ligand of $P$. acnes is so far unknown. We speculate that one or all of the surface-exposed RlpA-domain lipoproteins of $P$. acnes are TLR2 ligands. These lipoproteins are abundantly produced on the surface of $P$. acnes and they are not covered or protected from host cell contact by other surface structures, such as EPS or pili in $P$. avidum and $P$. granulosum, respectively. It will be interesting to investigate if $P$. avidum and $P$. granulosum are also able to trigger TLR2 responses, or if this is specific to $P$. acnes.

The colonization of human skin by $P$. acnes can be achieved by other strategies, such as factors that allow successful competition with other bacteria, including $P$. avidum and P. granulosum. Successful competition might include the efficient acquisition of nutrients from host components. In this respect, only $P$. acnes expressed surface-attached endoglycoceramidases, which might hydrolyze gangliosides on host cell membranes [43]. Another specific feature of $P$. acnes is the presence and 
the production of surface-exposed CAMP factors 1 and 2 . It has been shown that CAMP factor 2 has properties of a co-hemolysin $[17,24,25,44]$. Moreover, inhibition of CAMP2 by neutralizing antibodies efficiently attenuated $P$. acnes-induced inflammation in the mouse ear model [45], suggesting that CAMP2, and probably the other ones as well, are virulence factors of $P$. acnes. The corresponding camp1 and camp2 genes are absent in the genomes of P. granulosum and P.avidum. CAMP factors have been partially characterized in streptococcal species as co-hemolsyins and pore-forming toxins [46]. They are involved in the CAMP reaction, the lysis of sheep erythrocytes by the synergistic action of the sphingomyelinase $\mathrm{C}$ from S. aureus and CAMP factor from Group B Streptococcus strains [47]. The sphingomyelinase initially hydrolyzes sphingomyelin to ceramide (and phosphocholine) on the erythrocyte membrane, which renders the erythrocytes susceptible to the lytic activity of CAMP factor. It was recently shown that CAMP factor 2 of $P$. acnes can act as an exotoxin, exhibiting cytotoxic activity on host cells [25]. The study of Nakatsuji et al. further suggests that CAMP factor 2 acts together with host acid sphingomyelinase to amplify bacterial virulence, thus supporting the degradation and invasion of host cells. The gene for CAMP factor 2 is located within a small gene cluster that also contains genes encoding sialidases and a sialic acid transporter. This cluster seems to be inserted into the $P$. acnes genome (Figure 2). It is tempting to suggest a functional connection of these factors as host-interacting and/or virulence traits. One possible scenario is that sialidases act directly on host cell membrane exposed gangliosides, thus releasing terminal sialic acid residues that are taken up by the sialic acid transporter and used as energy source. The remaining ceramide moiety could be a binding site for CAMP factor 2, in analogy to the CAMP reaction. Another component in this scenario could be surface-associated endoglycoceramidases of $P$. acnes that is predicted to hydrolyze gangliosides on host cell membranes into ceramides and oligosaccharides.

Important questions remain to be answered, in particular regarding the host tissue and host cell interactions of these three species. Although all three species are colonizing human skin, it is not known if these species actually compete at those sites or have adapted to occupy unique niches through species-specific host interactions. The different surface properties of the three species suggest that they have different colonization strategies that could be host cell or tissue-specific at skin and non-skin sites.

\section{Conclusions}

Taken together, comparative genome analysis showed that CAMP factor 1 and 2 and other host-interacting traits (e.g. DsA1, DsA2, hyaluronate lyase, endoglycoceramidase, sialidase, linoleic acid isomerase) are encoded on smaller genomic regions that are either inserted into the genome of $P$. acnes or deleted from the genomes of $P$. avidum and $P$. granulosum. That might explain the greater versatility of $P$. acnes to interact with the human host. P. avidum and to a minor extent $P$. granulosum have their own speciesspecific genomic regions, that are absent from $P$. acnes. Among these are the EPS cluster of $P$. avidum and the pili/ fimbriae gene clusters of $P$. granulosum. Thus, humanassociated propionibacteria have evolved different hostinteracting strategies which are likely linked to different disease-causing potentials of these three species.

\section{Methods}

\section{Bacteria strains and culture}

P. avidum strain ATCC25577 and P. granulosum strain DSM20700 were obtained from DSMZ (German Collection of Microorganisms and Cell Cultures). P. acnes KPA171202 (KPA, type I-2) and P. acnes 266 (type IA) were previously isolated $[16,21]$. P. avidum TM16 and $P$. granulosum TM11 were isolated from radical prostatectomy specimens in our previous study [10]. All strains were cultured on Reinforced Clostridial Agar (Oxoid) plates for 3 days at $37^{\circ} \mathrm{C}$ under anaerobic conditions. For liquid cultures, plate-grown bacteria were resuspended and washed in brain heart infusion (BHI) broth (Sigma-Aldrich); BHI broth was inoculated with P. avidum ATCC25577 and P. granulosum DSM20700 $\left(\mathrm{OD}_{600} 0.01\right)$ and cultures were grown to exponential $\left(\mathrm{OD}_{600} 0.3-0.4\right)$ and stationary phases $\left(\mathrm{OD}_{600} 0.9-1.2\right)$ at $37^{\circ} \mathrm{C}$ under anaerobic conditions using the Gas-Pak ${ }^{\text {mo }}$ system (Oxoid). To ensure identical growth conditions due to the usage of the Gas-Pak system, all strains were cultured in the same GasPak container and the same BHI batch was used.

\section{DNA extraction and genome sequencing}

Genomic DNA from all strains of P. avidum TM16 and P. granulosum DSM20700 and TM11 were extracted using the MasterPure ${ }^{\mathrm{Tx}}$ Gram Positive DNA Purification Kit (Epicentre). The genomes were draft sequenced using Illumina/Solexa GAIIx machines at the Beijing Genomics Institute (BGI) (Shenzhen, China). The whole genome shotgun projects have been deposited at DDBJ/EMBL/GenBank under the accession numbers AOUA00000000 for $P$. avidum TM16, AOST00000000 for $P$. granulosum TM11 and AOSS00000000 for $P$. granulosum DSM20700. The versions described in this paper are the first versions, AOUA01000000, AOST00000000 and AOSS01000000, respectively.

\section{Sequence analysis}

Automatic annotations were performed by PGAAP, NCBI Prokaryotic Genome Automatic Annotation Pipeline [48]. To identify homologs in different species, 
comparisons were done with a protein sequence-based bidirectional BLAST approach (blastP version 2.2.18). Sequence homologies were only mentioned in this study for proteins with an amino acid identity of $>25 \%$ and an overlap of the query and subject sequence of $>75 \%$. Genome representations were created by DNA plotter (Sanger Institute). For nucleotide sequence comparisons the Artemis Comparison Tool (ACT) was used [49]. To identify genomic islands the Island Viewer was used, a computational tool that integrates three different genomic island prediction methods, i.e. IslandPick, IslandPath-DIMOB, and SIGI-HMM [50]. For the analysis and mapping of pathways of $P$. acnes KEGG and KEGG MAPPER were used (http://www.genome.jp/kegg/).

\section{Scanning electron microscopy}

Bacterial cells were fixed with $2.5 \%$ glutaraldehyde, postfixed using repeated incubations with $1 \%$ osmium tetroxide $/ 1 \%$ tannic acid, dehydrated with a graded ethanol series, critical-point dried and coated with $2 \mathrm{~nm}$ platinum. After dehydration and critical-point drying, the specimens were coated with $5 \mathrm{~nm}$ platinum/carbon and analyzed in a Leo 1550 scanning electron microscopy.

\section{Atomic force microscopy, fluorescence staining and confocal microscopy}

A NanoWizard II atomic force microscope (JPK Instruments, Germany) combined with an inverted optical microscope (Zeiss Axiovert 200 M, Zeiss, Germany) was used to record AFM images at 512 pixels per line, with $1 \mathrm{~Hz}$ scanning speed. Tapping mode in air was performed for imaging, using OMCL-AC160TS cantilevers (Olympus) with spring constant of $26 \mathrm{~N} / \mathrm{m}$. A glass coverslip was immersed in bacterial cells suspended in water, gently rinsed with water, briefly dried in air, and mounted for AFM imaging of the cells.

Staining of DNA and carbohydrates in the EPS was done by suspending bacterial cells in PBS and staining simultaneously with Calcofluor white (100 mg/l, SigmaAldrich) and propidium iodide (0.05 $\mathrm{mM}$, Invitrogen) for $30 \mathrm{~min}$. After one wash in PBS, the samples were resuspended with $\mathrm{PBS}$ and visualized using a confocal laser scanning microscope (LSM 700, Carl Zeiss), using $405 \mathrm{~nm}$ excitation for Calcofluor white, and $555 \mathrm{~nm}$ excitation for propidium iodide.

\section{Precipitation of extracellular proteins}

The exponential and stationary cultures were centrifuged for $15 \mathrm{~min}$ at $6,000 \times g$ and $4^{\circ} \mathrm{C}$. Supernatant was filtered through a $0.22-\mu \mathrm{m}$-pore-size membrane filter to remove residual bacteria. Extracellular proteins were precipitated using a modified trichloroacetic acid (TCA) method [51]. In brief, the filtrate $(100 \mathrm{ml})$ was mixed with $25 \%$ TCA to a final concentration of $6 \%$ and incubated overnight at $-20^{\circ} \mathrm{C}$. The mixture was centrifuged for $30 \mathrm{~min}\left(6,000 \times g\right.$ and $\left.4^{\circ} \mathrm{C}\right)$ and the resulting pellet was resuspended in $1 \mathrm{ml}$ of acetone. The mixture was centrifuged for $15 \mathrm{~min}\left(20,000 \times \mathrm{g}\right.$ and $\left.4^{\circ} \mathrm{C}\right)$, washed twice with acetone and the resulting pellet was air dried. The pellets were dissolved in PBS buffer and Laemmli sample before analyzed by SDS PAGE.

\section{Protein identification by MALDI-TOF-MS}

SDS PAGE was carried out with $12 \%$ acrylamide concentration of gels. Gels were stained with Coomassie Blue. Protein bands were excised for in-gel tryptic digestion. After concentration, the peptides were loaded onto the MALDI target plate using dried droplet method and analysed by MALDI-TOF-MS on a Bruker Autoflex (Bruker Daltonik) operating in reflector mode. Peptide mass fingerprinting (PMF) and MS/MS data were searched against a manually created propionibacteria database. Proteins were identified using MASCOT 2.3 (http:// www.matrixscience.com) allowing a peptide mass tolerance of 100-300 ppm and $\pm 0.3 \mathrm{Da}$ for the fragment mass tolerance. A maximum of one missed cleavage, oxidation of methionine, N-terminal acetylation of the peptide, propionamide at cysteine residues and $\mathrm{N}$-terminal pyroglutamic acid formation were considered in these searches. The identification criteria were: minimum 30\% sequence coverage; or minimum 15\% sequence coverage and one MS/MS confirmation; or sequence coverage below 15\% and at least two MS/MS confirmations.

\section{Surfome analysis}

The protocol for bacterial surface digestion was adapted from Doro et al. [28]. P. avidum strain ATCC25577, P. acnes KPA and P. granulosum strain DSM20700 strains were grown to $\mathrm{OD}_{600} 0.3$ - 0.4. Bacterial cells were harvested by centrifugation at $3,500 \times g$ for $10 \mathrm{~min}$ at $4^{\circ} \mathrm{C}$ and washed twice with PBS. Cells were resuspended in $800 \mu \mathrm{l}$ of PBS containing 40\% sucrose. Digestions were carried out with $10 \mu \mathrm{g}$ of trypsin (Promega) for $30 \mathrm{~min}$ at $37^{\circ} \mathrm{C}$. Bacterial cells were centrifuged at $3,500 \times g$ for $10 \mathrm{~min}$ at $4^{\circ} \mathrm{C}$ and the supernatants were filtered through $0.22-\mu \mathrm{m}$ pore size filters (Millipore). Protease reactions were stopped with formic acid at $0.1 \%$ final concentration. Before protein identification, PBS and sucrose were removed using ZipTip C18, $0.6 \mu$ l bed volume (Millipore). Peptides were eluted with $5 \mu \mathrm{ll} 60 \% \mathrm{ACN}, 0.1 \%$ TFA followed by $5 \mu \mathrm{l} 80 \% \mathrm{ACN}, 0.1 \%$ TFA. The combined eluates were concentrated using a Microconcentrator 5301 (Eppendorf) and kept at $-20^{\circ} \mathrm{C}$ until further analysis.

\section{Protein identification by UPLC/MS/MS}

The samples were solubilized in $12 \mu \mathrm{l}$ 2:98 (v/v) acetonitrile/ water containing $0.1 \%$ TFA $(\mathrm{v} / \mathrm{v})$. After concentration on a 
Acclaim PepMap 100 trap column at a flow rate of $5 \mu \mathrm{l} / \mathrm{min}$ (75 $\mu \mathrm{m} \times 2$ cm, C18, $3 \mu \mathrm{m}, 100 \AA$, Thermo Scientific) separation was performed by UHPLC (UltiMate 3000, Dionex) using a Acclaim PepMap RSLC column at a flow rate of $300 \mathrm{nl} / \mathrm{min}(75 \mu \mathrm{m} \times 150 \mathrm{~mm}, \mathrm{C} 18,2 \mu \mathrm{m}, 100 \AA$ A, Thermo Scientific). Mobile phase A was $0.1 \%(\mathrm{v} / \mathrm{v})$ TFA and B was 80:20 (v/v) acetonitrile/water containing 0.08\% (v/v) TFA. The elution gradients were $3-15 \%$ B for $2 \mathrm{~min}, 15-60 \%$ B for $60 \mathrm{~min}, 60-98 \%$ B for $4 \mathrm{~min}, 98 \%$ B for 2 min and $98-3 \%$ B for $3 \mathrm{~min} .312$ fractions per sample were spotted onto a MALDI template using a Probot microfraction collector (Dionex). Spotting frequency was 10 seconds and $\alpha$-cyano-4-hydroxycinnamic acid (0,5\% in 70:30 (v/v) acetonitrile/water containing $0.1 \%(\mathrm{v} / \mathrm{v})$ TFA) was added at a flow rate of $1 \mu \mathrm{l} / \mathrm{min}$. Mass spectra were acquired with a 4700 Proteomics Analyzer (Applied Biosystems) MALDI-TOF /TOF instrument. The MS mass range was 800-4000 Da. MS/MS precursor selection was performed automatically; using the 4000 Series Explorer Software 3.6 and a maximum of $7 \mathrm{MS} / \mathrm{MS}$ measurements per spot were allowed. MS/MS data were searched against a manually created propionibacteria database using MASCOT 2.3 (Matrix Science) allowing a peptide mass tolerance of $100-150 \mathrm{ppm}$ and $0.3 \mathrm{Da}$ for the fragment mass tolerance. Enzyme specificity was set to none. $\mathrm{N}$-acetyl (Protein), oxidation (M), pyro-glu (N-term Q) were considered in these searches and standard scoring and ions score cut-off 30 were used for data evaluation. The criterion for the identification of a protein was a minimum number of 3 peptides fulfilling the Mascot homology criteria.

\section{Availability of supporting data}

The Whole Genome Shotgun projects have been deposited at DDBJ/EMBL/GenBank under the accession AOST00000000 (http://www.ncbi.nlm.nih.gov/bioproject/ PRJNA189037), AOSS00000000 (http://www.ncbi.nlm.nih. gov/bioproject/PRJNA189038) and AOUA00000000 (http:// www.ncbi.nlm.nih.gov/bioproject/PRJNA189036). Other supporting data are included as Additional files 1, 2, 3, 4, 5,6 and 7.

\section{Additional files}

Additional file 1: Genome features of the propionibacterial species $P$. avidum, $P$. granulosum and $P$. acnes.

Additional file 2: A) Bidirectional Blast of all CDS of $P$. acnes KPA against other genomes of $P$. acnes, $P$. granulosum and $P$. avidum. B) Bidirectional Blast of all CDS of $P$. avidum 44067 against other genomes of $P$. avidum, $P$. acnes and $P$. granulosum. C) Bidirectional Blast of all CDS of $P$. granulosum TM11 against other genomes of $P$. granulosum, $P$. acnes and $P$. avidum. The color code represents the Blast e-values: White: >e-20; Light yellow: <e-20 and > e-50; Gold: <e-50 and > e-90; Light orange: $<\mathrm{e}-90$ and > e-100; Orange: <e-100 and > e-120; Red: <e-120.

Additional file 3: Comparative genome analysis of three cutaneous propionibacteria. A) Genome comparison with P. granulosum TM11 as the reference genome. B) Genome comparison with $P$. acnes KPA as the reference genome. Color code: CDS of $P$. granulosum TM11, marine; P. granulosum DSM20700, green; P. avidum ATCC25577, red; P. avidum TM16, orange; $P$. acnes KPA, blue; $P$. acnes 266 , light blue. The inner ring (in purple and olive) represents the $\mathrm{G}+\mathrm{C}$ content distribution of the reference genome (window size $10000 \mathrm{bp}$, step size $200 \mathrm{bp}$ ). The most inner circle depicts predicted islands (in red) acquired by horizontal gene transfer (predictions from IslandViewer; results from two different algorithms are included: orange, Sigi-HMM; blue, IslandPath-DIMOB). $P$. granulosum and $P$. acnes harbors 10 and 5 genomic regions, respectively, that are predicted to be horizontally acquired.

Additional file 4: Genes encoding host-interacting proteins of $P$. acnes are absent from the genome of $P$. avidum. Shown are four examples of genomic regions encoding putative host-interacting proteins of $P$. acnes that differ or are deleted in the genome of $P$. avidum ATCC25577. A) This $P$. acnes-specific region encodes a hyaluronidase (PPA0380) and contains 9 genes (PPA0372-PPA0382); several of them encode oxidoreductases and one encodes a glycosyl transferase. B) DsA1 (PPA2127) is a dermatan-sulphate adhesin with proline-threonine repeats [18]. The corresponding $P$. acnes-specific gene is replaced in P. avidum ATCC25577 by a larger island, encoding mostly proteins with unknown functions. C) DsA2 (PPA2210) is another dermatan-sulphate adhesin that is encoded in a region of $12 P$. acnes-specific genes that includes five genes putatively involved in carnitine catabolism. D) PPA1560 encodes the characterized sialidase of $P$. acnes [19]. P. avidum strain ATCC25577 encodes a different sialidase (HMPREF9153_0188; 63\% protein identity to PPA1560). In the genome of $P$. avidum 44067, the sialidase-encoding region is deleted (data not shown). Red bars/lines identify regions with high sequence similarity (>70\%).

Additional file 5: $P$. avidum produces an EPS structure. A) The genome of $P$. avidum harbors a gene cluster for exopolysaccharide biosynthesis (HMPREF9153_1223 to HMPREF9153_1257 in strain ATCC25577 and PALO_09550 to PALO_09690 in strain 44067). Most of the genes encode glycosyltransferases. See Additional file $2 \mathrm{~b}$ for the functional assignment of all CDS. A similar gene cluster exists in the genome of Rothia mucilaginosa, a Gram-positive bacterium producing a mucilaginous capsular material. Same colors and numbers depict homologies between CDS of $P$. avidum and R. mucilaginosa. B) Staining experiments using calcofluor white and propidium iodide were performed, recorded by confocal microscopy (z-series, layers taken from the surface of the cells (top left) to the center of the cells (bottom right)), to confirm the existence of a polysaccharide structure surrounding P. avidum ATCC25577 cells. Blue, polysaccharide; red, DNA.

Additional file 6: Secreted proteins of $P$. avidum and $P$. granulosum. A) P. avidum ATCC25577 and B) P. granulosum DSM20700 were grown in $\mathrm{BH}$ medium to exponential (E) and early stationary (S) phase. Secreted proteins were precipitated from culture supernatants and separated on a SDS-PAGE gel (12\%). Abundant bands (numbered) were subjected to MS identification (see Additional file 7 for all identified proteins). Under the applied growth conditions, the most abundantly secreted proteins of $P$. avidum and $P$. granulosum are a triacylglycerol lipase (band 5 in section A) and two lysophospholipases (bands 1 and 2 in section B), respectively.

Additional file 7: Identification of secreted and surface-exposed proteins of $P$. avidum, $P$. granulosum and $P$. acnes.

\section{Abbreviations}

CAMP: Christie-Atkins-Munch-Petersen; EPS: Exopolysaccharide.

\section{Competing interests}

The authors declare that they have no competing interests.

\section{Authors' contributions}

TNM and HB conceptualized and designed the study and analyzed data. MS carried out mass spectrometry experiments and analyzed data. EB and $\mathrm{HB}$ analyzed the genomes. GZ and RM performed atomic force microscopy. KSS and TFM provided material and advice. VB performed electron microscopy. TNM and HB wrote the manuscript and all authors reviewed and edited the manuscript. All authors read and approved the final manuscript. 


\section{Acknowledgements}

We would like to thank Ahmed Basim Abduljabar for technical assistance and the European Skin Research Foundation (ESRF) for funding (to HB).

\section{Author details}

'Department of Biomedicine, Aarhus University, Aarhus, Denmark. ${ }^{2}$ Proteomics Core Facility, Max Planck Institute for Infection Biology, Berlin, Germany. ${ }^{3}$ Institute of Microbiology and Genetics, Georg August University Goettingen, Goettingen, Germany. ${ }^{4}$ Interdisciplinary Nanoscience Center (iNANO), Aarhus University, Aarhus, Denmark. ${ }^{5}$ Department of Pathology, Johns Hopkins University School of Medicine, Baltimore, MD, USA ${ }^{6}$ Microscopy Core Facility, Max Planck Institute for Infection Biology, Berlin, Germany. 'Department of Molecular Biology, Max Planck Institute for Infection Biology, Berlin, Germany.

Received: 17 May 2013 Accepted: 17 September 2013

Published: 22 September 2013

\section{References}

1. Poonam, Pophaly SD, Tomar SK, De S, Singh R: Multifaceted attributes of dairy propionibacteria: a review. World J Microbiol Biotechnol 2012, 28:3081-3095.

2. Grice EA, Segre JA: The skin microbiome. Nat Rev Microbio/ 2011, 9:244-253.

3. Sharon I, Morowitz MJ, Thomas BC, Costello EK, Relman DA, Banfield JF: Time series community genomics analysis reveals rapid shifts in bacterial species, strains, and phage during infant gut colonization. Genome Res 2013, 23:111-120.

4. Furukawa A, Uchida K, Ishige Y, Ishige I, Kobayashi I, Takemura T, Yokoyama T, Iwai K, Watanabe K, Shimizu S, Ishida N, Suzuki Y, Suzuki T, Yamada T, Ito $\mathrm{T}$, Eishi Y: Characterization of Propionibacterium acnes isolates from sarcoid and non-sarcoid tissues with special reference to cell invasiveness, serotype, and trigger factor gene polymorphism. Microb Pathog 2009, 46:80-87.

5. Alexeyev OA, Marklund I, Shannon B, Golovleva I, Olsson J, Andersson C, Eriksson I, Cohen R, Elgh F: Direct visualization of Propionibacterium acnes in prostate tissue by multicolor fluorescent in situ hybridization assay. J Clin Microbiol 2007, 45:3721-3728.

6. Fassi Fehri L, Mak TN, Laube B, Brinkmann V, Ogilvie LA, Mollenkopf H, Lein M, Schmidt T, Meyer TF, Brüggemann H: Prevalence of Propionibacterium acnes in diseased prostates and its inflammatory and transforming activity on prostate epithelial cells. Int J Med Microbiol 2011, 301:69-78.

7. McGinley KJ, Webster GF, Leyden JJ: Regional variations of cutaneous propionibacteria. Appl Environ Microbiol 1978, 35:62-66.

8. Dessinioti C, Katsambas AD: The role of Propionibacterium acnes in acne pathogenesis: facts and controversies. Clin Dermatol 2010, 28:2-7.

9. Perry A, Lambert P: Propionibacterium acnes: infection beyond the skin. Expert Rev Anti Infect Ther 2011, 9:1149-1156.

10. Mak TN, Yu SH, De Marzo AM, Brüggemann H, Sfanos KS: Multilocus sequence typing (MLST) analysis of Propionibacterium acnes isolates from radical prostatectomy specimens. Prostate 2013, 73:770-777.

11. Panagea S, Corkill JE, Hershman MJ, Parry CM: Breast abscess caused by Propionibacterium avidum following breast reduction surgery: case report and review of the literature. J Infect 2005, 51:e253-e255.

12. Vohra A, Saiz E, Chan J, Castro J, Amaro R, Barkin J: Splenic abscess caused by Propionibacterium avidum as a complication of cardiac catheterization. Clin Infect Dis 1998, 26:770-771.

13. Janvier $F$, Delacour $H$, Larréché $S$, Abdalla $S$, Aubert $P$, Mérens A: Abdominal wall and intra-peritoneal abscess by Propionibacterium avidum as a complication of abdominal parietoplasty. Pathol Biol 2013. in press,

14. Armstrong RW, Wuerflein RD: Endocarditis due to Propionibacterium granulosum. Clin Infect Dis 1996, 23:1178-1179.

15. Eishi Y, Suga M, Ishige I, Kobayashi D, Yamada T, Takemura T, Takizawa T, Koike M, Kudoh S, Costabel U, Guzman J, Rizzato G, Gambacorta M, du Bois R, Nicholson AG, Sharma OP, Ando M: Quantitative analysis of mycobacterial and propionibacterial DNA in lymph nodes of Japanese and European patients with sarcoidosis. J Clin Microbiol 2002, 40:198-204.

16. Brüggemann $\mathrm{H}$, Henne A, Hoster F, Liesegang $\mathrm{H}$, Wiezer A, Strittmatter A, Hujer S, Dürre P, Gottschalk G: The complete genome sequence of Propionibacterium acnes, a commensal of human skin. Science 2004, 305:671-673.

17. Valanne S, McDowell A, Ramage G, Tunney MM, Einarsson GG, O'Hagan S, Wisdom GB, Fairley D, Bhatia A, Maisonneuve JF, Lodes M, Persing DH, Patrick S:
CAMP factor homologues in Propionibacterium acnes: a new protein family differentially expressed by types I and II. Microbiology 2005, 151:1369-1379.

18. Lodes MJ, Secrist H, Benson DR, Jen S, Shanebeck KD, Guderian J, Maisonneuve JF, Bhatia A, Persing D, Patrick S, Skeiky YA: Variable expression of immunoreactive surface proteins of Propionibacterium acnes. Microbiology 2006, 152:3667-3681.

19. McDowell A, Gao A, Barnard E, Fink C, Murray PI, Dowson CG, Nagy I, Lambert PA, Patrick S: A novel multilocus sequence typing scheme for the opportunistic pathogen Propionibacterium acnes and characterization of type I cell surface-associated antigens. Microbiology 2011, 157:1990-2003.

20. Nakatsuji T, Liu YT, Huang CP, Zouboulis CC, Gallo RL, Huang CM: Vaccination targeting a surface sialidase of $P$. acnes: implication for new treatment of acne vulgaris. PLOS One 2008, 3:e1551.

21. Brzuszkiewicz E, Weiner J, Wollherr A, Thürmer A, Hüpeden J, Lomholt HB, Kilian M, Gottschalk G, Daniel R, Mollenkopf HJ, Meyer TF, Brüggemann H: Comparative genomics and transcriptomics of Propionibacterium acnes. PLoS One 2011, 6:e21581

22. Ordögh L, Hunyadkürti J, Vörös A, Horváth B, Szucs A, Urbán E, Kereszt A, Kondorosi E, Nagy I: Complete genome sequence of Propionibacterium avidum strain 44067, isolated from a human skin abscess. Genome Announc 2013. in press.

23. Holland C, Mak TN, Zimny-Arndt U, Schmid M, Meyer TF, Jungblut PR, Brüggemann H: Proteomic identification of secreted proteins of Propionibacterium acnes. BMC Microbiol 2010, 10:230.

24. Lo CW, Lai YK, Liu YT, Gallo RL, Huang CM: Staphylococcus aureus hijacks a skin commensal to intensify its virulence: immunization targeting $\beta$-hemolysin and CAMP factor. J Invest Dermatol 2011, 131:401-409.

25. Nakatsuji T, Tang DC, Zhang L, Gallo RL, Huang CM: Propionibacterium acnes CAMP factor and host acid sphingomyelinase contribute to bacterial virulence: potential targets for inflammatory acne treatment. PLoS One 2011, 6:e14797.

26. Yamane K, Nambu T, Yamanaka T, Mashimo C, Sugimori C, Leung KP, Fukushima H: Complete genome sequence of Rothia mucilaginosa DY-18: a clinical isolate with dense meshwork-like structures from a persistent apical periodontitis lesion. Sequencing 2010, 2010:457236.

27. Rogers EA, Das A, Ton-That $\mathrm{H}$ : Adhesion by pathogenic corynebacteria. Adv Exp Med Biol 2011, 715:91-103.

28. Doro F, Liberatori S, Rodríguez-Ortega MJ, Rinaudo CD, Rosini R, Mora M, Scarselli M, Altindis E, D'Aurizio R, Stella M, Margarit I, Maione D, Telford JL, Norais N, Grandi G: Surfome analysis as a fast track to vaccine discovery: identification of a novel protective antigen for Group B Streptococcus hyper virulent strain $\mathrm{COH} 1$. Mol Cell Proteomics 2009, 8:1728-1737.

29. Boels IC, Beerthuyzen MM, Kosters MH, Van Kaauwen MP, Kleerebezem M, De Vos WM: Identification and functional characterization of the Lactococcus lactis rfb operon, required for dTDP-rhamnose biosynthesis. J Bacteriol 2004, 186:1239-1248.

30. Annunziato PW, Wright LF, Vann WF, Silver RP: Nucleotide sequence and genetic analysis of the neuD and neuB genes in region 2 of the polysialic acid gene cluster of Escherichia coli K1. J Bacteriol 1995, 177:312-319.

31. Freeman BC, Chen C, Beattie GA: Identification of the trehalose biosynthetic loci of Pseudomonas syringae and their contribution to fitness in the phyllosphere. Environ Microbiol 2010, 12:1486-1497.

32. Ryder C, Byrd M, Wozniak DJ: Role of polysaccharides in Pseudomonas aeruginosa biofilm development. Curr Opin Microbiol 2007, 10:644-648.

33. Alhede M, Bjarnsholt T, Jensen PØ, Phipps RK, Moser C, Christophersen L, Christensen LD, van Gennip M, Parsek M, Høiby N, Rasmussen TB, Givskov M: Pseudomonas aeruginosa recognizes and responds aggressively to the presence of polymorphonuclear leukocytes. Microbiology 2009, 155:3500-3508.

34. Byrd MS, Pang B, Mishra M, Swords WE, Wozniak DJ: The Pseudomonas aeruginosa exopolysaccharide Psl facilitates surface adherence and NF-kappaB activation in A549 cells. MBio 2010, 1.

35. Cabrera M, Gil I, Rodriguez D: Growth of Propionibacterium acnes strains on semisynthetic medium; antigenic polysaccharide production. Zentralb/ Mikrobiol 1983, 138:391-395.

36. Cummins CS, White RH: Isolation, identification, and synthesis of 2 , 3-diamino-2,3-dideoxyglucuronic acid: a component of Propionibacterium acnes cell wall polysaccharide. J Bacterio/ 1983, 153:1388-1393.

37. Squaiella CC, Longhini AL, Braga EG, Mussalem JS, Ananias RZ, Yendo TM, Straus AH, Toledo MS, Takahashi HK, Hirata IY, Longo-Maugéri IM: Modulation of the type I hypersensitivity late phase reaction to OVA by Propionibacterium acnes-soluble polysaccharide. Immunol Lett 2008, 121:157-166. 
38. Whale GA, Sutcliffe IC, Morrisson AR, Pretswell EL, Emmison N: Purification and characterisation of lipoglycan macroamphiphiles from Propionibacterium acnes. Antonie Van Leeuwenhoek 2004, 86:77-85.

39. Mandlik A, Swierczynski A, Das A, Ton-That H: Corynebacterium diphtheriae employs specific minor pilins to target human pharyngeal epithelial cells. Mol Microbiol 2007, 64:111-124.

40. Schmaler M, Jann NJ, Ferracin F, Landolt LZ, Biswas L, Götz F, Landmann R: Lipoproteins in Staphylococcus aureus mediate inflammation by TLR2 and iron-dependent growth in vivo. J Immunol 2009, 182:7110-7118.

41. Kim J: Review of the innate immune response in acne vulgaris: activation of Toll-like receptor 2 in acne triggers inflammatory cytokine responses. Dermatology 2005, 211:193-198.

42. Kim J, Ochoa MT, Krutzik SR, Takeuchi O, Uematsu S, Legaspi AJ, Brightbill HD, Holland D, Cunliffe WJ, Akira S, Sieling PA, Godowski PJ, Modlin RL: Activation of toll-like receptor 2 in acne triggers inflammatory cytokine responses. J Immunol 2002, 169:1535-1541.

43. Sakaguchi K, Okino N, Sueyoshi N, Izu H, Ito M: Cloning and expression of gene encoding a novel endoglycoceramidase of Rhodococcus sp. strain C9. J Biochem 2000, 128:145-152.

44. Sörensen M, Mak TN, Hurwitz R, Ogilvie LA, Mollenkopf HJ, Meyer TF, Brüggemann $\mathrm{H}$ : Mutagenesis of Propionibacterium acnes and analysis of two CAMP factor knock-out mutants. J Microbiol Methods 2010, 83:211-216.

45. Liu PF, Nakatsuji T, Zhu W, Gallo RL, Huang CM: Passive immunoprotection targeting a secreted CAMP factor of Propionibacterium acnes as a novel immunotherapeutic for acne vulgaris. Vaccine 2011, 29:3230-3238.

46. Liu GY, Nizet V: Extracellular virulence factors of group B Streptococci. Front Biosci 2004, 9:1794-1802.

47. Christie $R$, Atkins $N E$, Munch-Petersen E: A note on a lytic phenomenon shown by group B streptococci. Aust J Exp Biol 1944, 22:197-200.

48. Angiuoli SV, Gussman A, Klimke W, Cochrane G, Field D, Garrity G, Kodira CD, Kyrpides N, Madupu R, Markowitz V, Tatusova T, Thomson N, White O: Toward an online repository of Standard Operating Procedures (SOPs) for (meta) genomic annotation. OMICS 2008, 12:137-141.

49. Carver TJ, Rutherford KM, Berriman M, Rajandream MA, Barrell BG, Parkhill J: ACT: the Artemis Comparison Tool. Bioinformatics 2005, 21:3422-3423.

50. Langille MG, Brinkman FS: Island viewer: an integrated interface for computational identification and visualization of genomic islands. Bioinformatics 2009, 25:664-665.

51. Komoriya K, Shibano N, Higano T, Azuma N, Yamaguchi S, Aizawa S: Flagellar proteins and type III-exported virulence factors are the predominant proteins secreted into the culture media of Salmonella typhimurium. Mol Microbiol 1999, 34:767-779.

doi:10.1186/1471-2164-14-640

Cite this article as: Mak et al:: Comparative genomics reveals distinct host-interacting traits of three major human-associated propionibacteria. BMC Genomics 2013 14:640.

\section{Submit your next manuscript to BioMed Central and take full advantage of:}

- Convenient online submission

- Thorough peer review

- No space constraints or color figure charges

- Immediate publication on acceptance

- Inclusion in PubMed, CAS, Scopus and Google Scholar

- Research which is freely available for redistribution 